eCommons@AKU

THE AGA KHAN UNIVERSITY

Medical College, Pakistan

Department of Biological \& Biomedical Sciences

Medical College, Pakistan

November 2008

\title{
Blood Pressure Lowering and Vasomodulator Effects of Piperine
}

Syed Intasar Husain Taqvi

Abdul Jabbar Shah

Aga Khan University

Anwar Gilani

Aga Khan University

Follow this and additional works at: http://ecommons.aku.edu/pakistan_fhs_mc_bbs

Part of the Cardiology Commons, and the Pharmacology Commons

\section{Recommended Citation}

Taqvi, S., Shah, A., Gilani, A. (2008). Blood Pressure Lowering and Vasomodulator Effects of Piperine. Journal of Cardiovascular Pharmacology, 52(5), 452-458.

Available at: http://ecommons.aku.edu/pakistan_fhs_mc_bbs/48 


\title{
Blood Pressure Lowering and Vasomodulator Effects of Piperine
}

\author{
Syed Intasar Husain Taqvi, PhD, ${ }^{* \dagger}$ Abdul Jabbar Shah, PhD, $† \neq$ and \\ Anwarul Hassan Gilani, PhD $\dagger$
}

\begin{abstract}
This study was aimed to explore underlying mechanism(s) of cardiovascular effects of piperine. Intravenous administration of piperine caused a dose-dependent ( 1 to $10 \mathrm{mg} / \mathrm{kg}$ ) decrease in mean arterial pressure (MAP) in normotensive anesthetized rats; the next higher dose $(30 \mathrm{mg} / \mathrm{kg})$ did not cause any further change in MAP. The fall in blood pressure (BP) was followed by small increase in MAP after each dose. In Langendorrf's rabbit heart preparation, piperine caused partial inhibition and verapamil caused complete inhibition of force and rate of ventricular contractions and coronary flow. In rabbit aortic rings, piperine inhibited high $\mathrm{K}^{+}(80 \mathrm{mM})$ precontractions and partially inhibited phenylephrine (PE), suggesting $\mathrm{Ca}^{2+}$ channel blockade (CCB), which was further confirmed when pretreatment of tissues with piperine caused rightward shift in $\mathrm{Ca}^{2+}$ concentrationresponse curves, similar to verapamil. In $\mathrm{Ca}^{2+}$-free medium, piperine (1 to $30 \mu \mathrm{M}$ ) exhibited vasoconstrictor effect. In rat aorta, piperine demonstrated endothelium-independent vasodilator effect and was more potent against high $\mathrm{K}^{+}$precontractions than $\mathrm{PE}$. In bovine coronary artery preparations, piperine inhibited high $\mathrm{K}^{+}$precontractions completely. These data indicate that piperine possesses a blood pressure-lowering effect mediated possibly through CCB, while consistent decrease in BP was restricted by associated vasoconstrictor effect. Additionally, species selectivity exists in the $\mathrm{CCB}$ effect of piperine.
\end{abstract}

Key Words: piperine, antihypertensive, vasorelaxation, calcium antagonist, vasoconstriction, vasomodulator

(J Cardiovasc Pharmacol ${ }^{\mathrm{TM}}$ 2008;52:452-458)

\section{INTRODUCTION}

Piperine is a pungent alkaloid isolated from Piper longum L. and Piper nigrum L. species, which contain piperidine ring (Figure 1) ${ }^{1}$. Piperine has not been studied

Received for publication July 7, 2008; accepted September 5, 2008.

From the Department of Pharmaceutical Sciences; Federal Urdu University of Arts, Science and Technology, Gulshan Campus Karachi-75300, Pakistan; $\nmid$ Drug Discovery and Natural Products Research Unit, Department of Biological and Biomedical Sciences, Aga Khan University Medical College, Karachi-74800, Pakistan; and $\$$ Department of Pharmaceutical Sciences, COMSATS, Institute of Information Technology, University Road Abbottabad-22060, Pakistan.

This study was partially supported by the research grant from Pakistan Science Foundation.

The authors state that they have no financial interest in the products mentioned within this article.

Reprints: Anwarul Hassan Gilani, PhD, Professor of Pharmacology, Department of Biological and Biomedical Sciences, Aga Khan University Medical College, Karachi-74800, Pakistan(e-mail: anwar.gilani@aku.edu). Copyright $(\subset) 2008$ by Lippincott Williams \& Wilkins extensively for its cardiovascular effects, except for a few preliminary reports. A mixture of piperine and piperdardine showed antihypertensive effect in rat $^{2}$ without describing the underlying mechanism(s). Piperine has been found without direct effect on the heart, although it exhibited positive chronotropic and inotropic effects mediated through the release of calcitonin gene-related peptide from nonadrenergic and noncholinergic nerves in isolated rat atria. ${ }^{3}$ Additionally, piperine also possesses antiplatelet, ${ }^{4}$ antipyretic and analgesic, ${ }^{5}$ antiinflammatory, ${ }^{6}$ and antidepressant ${ }^{7}$ characteristics. Piperine also exhibits a contractile effect in urinary bladder, which is mediated through transient receptor potential vanilloid 1 (TRPV1). ${ }^{8}$ Apart from these cardiovascular effects, many diverse biological activities of piperine have been comprehensively reviewed recently. ${ }^{9}$

Our previous studies show that piperidine derivatives perform direct action on cardiac muscle, exhibiting a cardiodepressant effect mediated through calcium channel blockade. $^{10,11}$ Our recent study $^{12}$ demonstrates that piperine mediates spasmolytic effect through calcium antagonism. On the basis of these observations and the heterogeneous nature of calcium channels, ${ }^{13}$ we studied the effect of piperine on blood pressure and demonstrated that it lowers blood pressure at lower doses; at higher doses, the decrease in blood pressure is accompanied by vasoconstrictor effect.

\section{MATERIALS AND METHODS}

\section{Drugs and Standards}

The following reference chemicals were obtained from the sources specified: acetylcholine chloride, atropine sulfate, $\mathrm{N}_{\omega}$-nitro-L-arginine methyl ester hydrochloride (L-NAME), norepinephrine hydrochloride, phenylephrine hydrochloride, verapamil hydrochloride and ethyleneglycoltetraacetic acid (EGTA) (Sigma Chemical Company, St. Louis, MO), piperine (Sigma-Aldrich Cemie GmbH, Germany), and Tween80 (Chemie S.S., La Jota, Barcleona, Spain). Heparin injections were purchased from Rotex Medica (Trittau, Germany), and pentothal sodium was obtained from Abbott Laboratories, Pakistan. All chemicals used were of the highest purity grade. Stock solutions were made in saline, whereas piperine was dissolved in Tween80; the dilutions were made fresh on the day of experiment.

\section{Animals}

Experiments performed complied with the rulings of the Institute of Laboratory Animal Resources, Commission on 


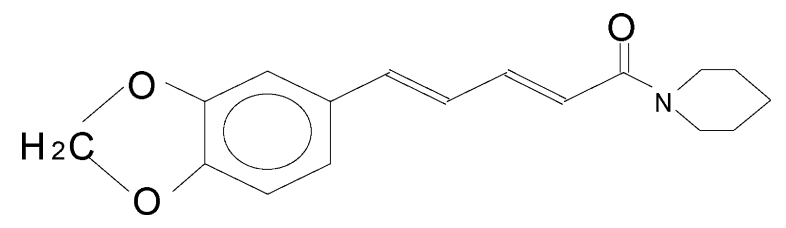

FIGURE 1. Structure of piperine.

Life Sciences, National Research Council ${ }^{14}$ and were approved by the Ethical Committee of Aga Khan University, Karachi. Sprague-Dawley (SD) male rats (200 to $250 \mathrm{~g}$ ) and local male rabbits (1.5 to $2 \mathrm{~kg}$ ) were housed in the animal house of Aga Khan University under controlled environment $\left(23\right.$ to $\left.25^{\circ} \mathrm{C}\right)$. Animals were fed standard diet consisting of (in $\mathrm{g} / \mathrm{kg}$ ): flour 380 , choker 380 , molasses 12 , salt 5.8 , nutrivetL 2.5 , potassium metabisulphate 1.2 , vegetable oil 38 , fish meal 170, and powdered milk 150 and were given tap water ad libitum.

The bovine hearts were collected freshly from a local slaughter house and placed in normal Krebs solution. Coronary vessel was isolated and extravascular tissues were trimmed off in the laboratory.

\section{Measurement of Blood Pressure in Normotensive Anesthetized Rats}

These experiments were performed on SD male rats (200 to $250 \mathrm{~g}$ ) as described previously. ${ }^{15}$ Animals were anesthetized with an i.p injection of sodium thiopental (Pentothal, 90 to $100 \mathrm{mg} / \mathrm{kg}$ ) and were fixed in a supine position on a dissecting table, a small mid-tracheal incision (approximately $1 \mathrm{~cm}$ ) was made to expose trachea, right jugular vein, and left carotid artery. The trachea was cannulated with a polyethylene tubing PE-20 and cleaned from time to time to maintain the spontaneous respiration. The right jugular vein was cannulated with a polyethylene tubing PE-50 to facilitate the intravenous administration of the standard drugs and test compounds. The carotid artery was cannulated with the similar tubing filled with heparinized $(60 \mathrm{IU} / \mathrm{mL})$ saline to prevent clotting of blood and connected to a pressure transducer with cable kit (MLT 1199) coupled with Power Lab data acquisition system (ADInstruments, Sydney, Australia). This connection was used for blood pressure recording. The exposed surface for the cannulation was covered with a piece of tissue paper moistened in warm saline. Body temperature of the animal was maintained by using an overhead lamp.

Animals were allowed to equilibrate for at least 20 minutes before the administration of any drug or test compound. Control responses of standards, such as acetylcholine (ACh, $1 \mu \mathrm{g} / \mathrm{kg}$ ) and norepinephrine (NE, $1 \mu \mathrm{g} / \mathrm{kg}$ ) were obtained before the testing of piperine. A change in mean arterial pressure (MAP) was recognized as the difference between the steady-state value before and the lowest reading after injection. The MAP was determined from the sum of diastolic blood pressure plus $1 / 3$ pulse width. Changes in MAP were expressed as percent of control values obtained immediately before the administration of test substance. The blood pressure was allowed to return to normal before the next dose was added, and the doses mentioned in the text represent the actual dose added each time.

\section{Langendorrf's Isolated Rabbit Heart}

The nonworking whole heart of male rabbit ${ }^{16}$ was used, and the protocol was followed as described earlier. ${ }^{10,11}$ As per protocol, heparin $(60 \mathrm{IU} / \mathrm{kg}$ ) was injected (i.p) 1 hour before isolation of heart, euthanized by cervical dislocation. Heart was excised rapidly and cannulated at the base of the aortic arch and mounted on Langendorrf's apparatus as quickly as possible; heart was perfused in a retrograde fashion, with Krebs-Henseliet solution at constant flow of 12 to $18 \mathrm{~mL} / \mathrm{min}$, and aerated with $5 \% \mathrm{CO}_{2}$ in $\mathrm{O}_{2}$ (Carbogen) of thermostatically controlled temperature at $37^{\circ} \mathrm{C}$ with $\mathrm{pH}$ of 7.4. The composition of Krebs-Henseliet solution was (in $\mathrm{mM}$ ): $\mathrm{NaCl} 117, \mathrm{KCl}$ 1.41, $\mathrm{MgSO}_{4} \cdot 7 \mathrm{H}_{2} \mathrm{O} 1.2, \mathrm{KH}_{2} \mathrm{PO}_{4} 1.1$, glucose 5.0, $\mathrm{NaHCO}_{3}$ 2.5, and $\mathrm{CaCl}_{2} 2.5$. A ventricular hook was placed through the apex of the spontaneously beating ventricle and connected via a pulley to a force transducer (model FT-03). Ventricular activity was transmitted by Harvard isotonic transducers and recorded through Student Oscillograph. Heart showing any abnormal rhythm was discarded.

\section{Rabbit Aorta}

As described previously, ${ }^{15}$ rats were killed by cervical dislocation, and the descending thoracic aorta was isolated and cut into 2 to $3 \mathrm{~mm}$ wide rings; each ring was mounted in a $5 \mathrm{~mL}$ tissue bath containing normal Krebs solution maintained at $37^{\circ} \mathrm{C}$ and aerated with carbogen. The composition of normal Krebs solution was (in $\mathrm{mM}$ ): $\mathrm{NaCl} 118.2, \mathrm{KCl} 4.7, \mathrm{NaHCO}_{3}$ 25.0, $\mathrm{CaCl}_{2} 2.5, \mathrm{KH}_{2} \mathrm{PO}_{4} 1.3, \mathrm{MgSO}_{4} 1.2$, and glucose 11.7 (pH 7.4). A resting tension of $2 \mathrm{~g}$ was applied to each tissue, and an equilibrium period of 1 hour was allowed before experimentation. Changes in tension were recorded by World Precision Instrument (WPI) through isometric force transducers (Fort-100) connected to Transbridge 4M and displayed on a computer via Power Lab (ML845) data acquisition system (ADInstruments, Sydney, Australia).

After 1 hour equilibrium period, tissues were stabilized by fixed concentration of phenylephrine (PE, $1 \mu \mathrm{M})$. The tissues were considered stable only when similar responses were displayed after repeated application of PE $(1 \mu \mathrm{M})$. Effect of the piperine or verapamil was first determined on the resting baseline of the tissue for possible vasoconstrictor effect. The effect of test compound and standard drugs were later tested against the agonists; PE $(1 \mu \mathrm{M})$ and high $\mathrm{K}^{+}(80 \mathrm{mM})$ induced contractions. The ability of the test compound to relax high $\mathrm{K}^{+}$-induced contractions possibly indicates a voltagedependent calcium channel blocking (CCB) effect; whereas inhibition of the PE-induced contractions is indicative of the blockade of $\mathrm{Ca}^{2+}$ influx through receptor-operated calcium channels (ROCCs) or $\mathrm{Ca}^{2+}$ release from the internal store(s). ${ }^{17}$ To confirm the CCB activity, $\mathrm{Ca}^{2+}$ concentration-response curves (CRC) were constructed in $\mathrm{Ca}^{2+}$-free medium. Then the effect of the increasing concentrations of the test compound was determined on the $\mathrm{Ca}^{2+} \mathrm{CRCs}$. The rightward shift in the $\mathrm{Ca}^{2+}$ CRCs was considered to possess CCB activity.

To determine if the test compound was inhibiting the $\mathrm{Ca}^{2+}$ release from intracellular stores, the effect of increasing 
concentrations of the test compound was tested against the PE $(1 \mu M)$ initial peak formation in $\mathrm{Ca}^{2+}$-free medium. The composition of $\mathrm{Ca}^{2+}$-free Krebs solution was prepared by omitting $\mathrm{CaCl}_{2}$ from the normal Krebs with addition of EGTA $(0.1 \mathrm{mM})$ to ensure total elimination of extracellular $\mathrm{Ca}^{2+} .{ }^{18}$ Changes in isometric tensions of the rings were measured through a force transducer (Fort-100, WPI, UK) coupled with bridge amplifier (Transbridge TBM4) and Power Lab (ML845) data acquisition system (ADInstruments, Sydney, Australia).

\section{Rat Aorta}

The procedure of Furchgott and Zawadski ${ }^{19}$ was followed with some modifications; descending thoracic aorta was isolated from male rats, and care was observed to avoid damage to the endothelium. Approximately $3 \mathrm{~mm}$ wide rings were mounted in a $5 \mathrm{~mL}$ tissue bath containing normal Krebs solution, maintained at $37^{\circ} \mathrm{C}$, and aerated with carbogen. A preload of $1 \mathrm{~g}$ was applied to each preparation and allowed to incubate for 30 minutes before exposure to any compound. After the equilibrium period of 30 minutes, the tissue was stabilized with repeated concentrations of PE $(1 \mu \mathrm{M})$. The integrity of endothelium was confirmed by the ability of the tissues to produce relaxation to $\mathrm{ACh}(0.1 \mu \mathrm{M})$. The endothelium lining of the tissues was removed by gentle rubbing with forceps, which resulted in the disappearance of this relaxation to ACh. To see whether the vasodilator effect of the test compound is endothelium-dependent, the effect of the compound was repeated in the presence of L-NAME $(0.1 \mu \mathrm{M})$ and in denuded aortic rings. ${ }^{20,21}$

\section{Bovine Left Descending Coronary Artery}

The protocol of Campbell et $\mathrm{al}^{22}$ was followed with some modifications; fresh bovine hearts were collected from a local slaughterhouse, and left descending coronary artery were dissected and cleaned of connective tissue in normal Krebs solution. The artery was cut into 2- to 3-mm diameter rings, mounted in 5-mL tissue baths containing normal Krebs solution, maintained at $37^{\circ} \mathrm{C}$, and aerated with carbogen. Vessels were equilibrated for 1.5 hours under $2 \mathrm{~g}$ of resting tension. High $\mathrm{K}^{+}(40 \mathrm{mM})$ was added to the bath until reproducible maximal contractions were obtained. Tension was recorded and analyzed through a force transducer (Fort100, WPI, UK), coupled with bridge amplifier (Transbridge TBM4) and Power Lab (ML 845) data acquisition system (ADInstruments, Sydney, Australia).

\section{Statistical Analysis}

Data expressed are mean \pm standard error (SEM, $n=$ number of experiments) and the median effective concentration ( $\mathrm{EC}_{50}$ values) with $95 \%$ confidence intervals $(\mathrm{CI})$. The statistical parameter applied is the Student $t$ test with $P<0.05$ as significantly different. Concentration response curves were analyzed by nonlinear regression using GraphPAD graphing software version 4 (GraphPAD, San Diego, CA).

\section{RESULTS}

\section{Effect on Blood Pressure in Normotensive Anesthetized Rat}

Intravenous administration of piperine caused a dosedependant decrease in MAP at 1 to $10 \mathrm{mg} / \mathrm{kg}$ in normotensive anesthetized rats; next dose of $30 \mathrm{mg} / \mathrm{kg}$ did not produce further decline in MAP, whereas additional increase in dose $(100 \mathrm{mg} / \mathrm{kg})$ caused little decline in BP, suggesting the involvement of some vasoconstricting mechanism(s) at higher doses. The fall in BP was followed by a slight increase in BP after each dose and a return to normal within a few minutes (Figure 2A). The percent declines in MAP at the respective doses of $1,3,10,30$, and $100 \mathrm{mg} / \mathrm{kg}$ were $9.34 \pm 5.45$, $22.37 \pm 5.42,30.34 \pm 4.40,34.62 \pm 4.31$, and $20.33 \pm 1.45$ $\mathrm{mmHg}$, respectively (Figure 2B). Whereas under similar experimental conditions, verapamil caused dose-dependent decrease in MAP, with percent declines of $4.57 \pm 2.10$, $13.93 \pm 1.73,30.40 \pm 1.61,40.10 \pm 5.60$, and $55.20 \pm 2.71$ $\mathrm{mmHg}$ at respective doses (Figure 2C).

\section{Effect on Langendorrf's Isolated Rabbit Heart}

When piperine was tested in isolated rabbit heart mounted in the Langendorrf's apparatus, piperine (0.01 to $10 \mu \mathrm{M})$ induced partial inhibition with maximum effect around $70 \%$ on the force and rate of ventricular contractions and coronary flow (Figure $3 \mathrm{~A}$ ) with respective $\mathrm{EC}_{50}$ values of 2.65 (95\% CI, 1.38 to 5.06), 5.29 (95\% CI, 2.67 to 10.49$)$, and $1.16 \mu \mathrm{M}(95 \% \mathrm{CI}, 0.56$ to 2.44$)$. Under similar experimental conditions, verapamil caused complete inhibition of the force, rate, and coronary flow (Figure $3 \mathrm{~B}$ ), with respective $\mathrm{EC}_{50}$ values of 1.18 ( $95 \% \mathrm{CI}, 0.72$ to 1.91$), 0.42$ (95\% CI, 0.22 to $0.78)$, and $3.22 \mu \mathrm{M}$ (95\% CI, 1.93 to 5.37 ).

\section{Effect on Rabbit Aorta}

When tested in isolated rabbit aortic preparations against contractions induced by high $\mathrm{K}^{+}$, cumulative addition of piperine caused complete relaxation with $\mathrm{EC}_{50}$ values of 30.93 $\mu \mathrm{M}(95 \% \mathrm{CI}, 14.80$ to 64.65$)$; it partially relaxed the PE precontractions (Figure 4A), and verapamil caused complete inhibition of high $\mathrm{K}^{+}$and PE precontractions with respective $\mathrm{EC}_{50}$ values of $0.10(95 \% \mathrm{CI}, 0.05$ to 0.18$)$ and $0.12 \mu \mathrm{M}(95 \%$ CI, 0.07 to 0.25 ) (Figure 4B). Pretreatment of aortic rings with piperine (30 to $100 \mu \mathrm{M}$ ) induced concentration-dependent rightward shift in the $\mathrm{Ca}^{2+} \mathrm{CRCs}$, constructed in $\mathrm{Ca}^{2+}$-free medium (Figure 4C) similar to that caused by verapamil (Figure 4D). When tested on baseline tension in $\mathrm{Ca}^{2+}$-free medium, cumulative addition of piperine caused contractile effect (Figure 4A). However, in aortic rings incubated in $\mathrm{Ca}^{2+}$ free medium, piperine pretreatment had no inhibitory effect on the initial PE peaks formation (data not shown).

\section{Effect on Rat Aorta}

When tested in isolated rat aorta preparations, cumulative addition of piperine induced endothelium-independent relaxation (Figure 5A), similar to verapamil (Figure 5B). The respective $\mathrm{EC}_{50}$ values of piperine in the intact and denuded endothelium aortic rings were 25.09 (95\% CI, 19.69 to 31.96) and $23.67 \mu \mathrm{M}(95 \% \mathrm{CI}, 13.30$ to 42.12$)$. Piperine also 

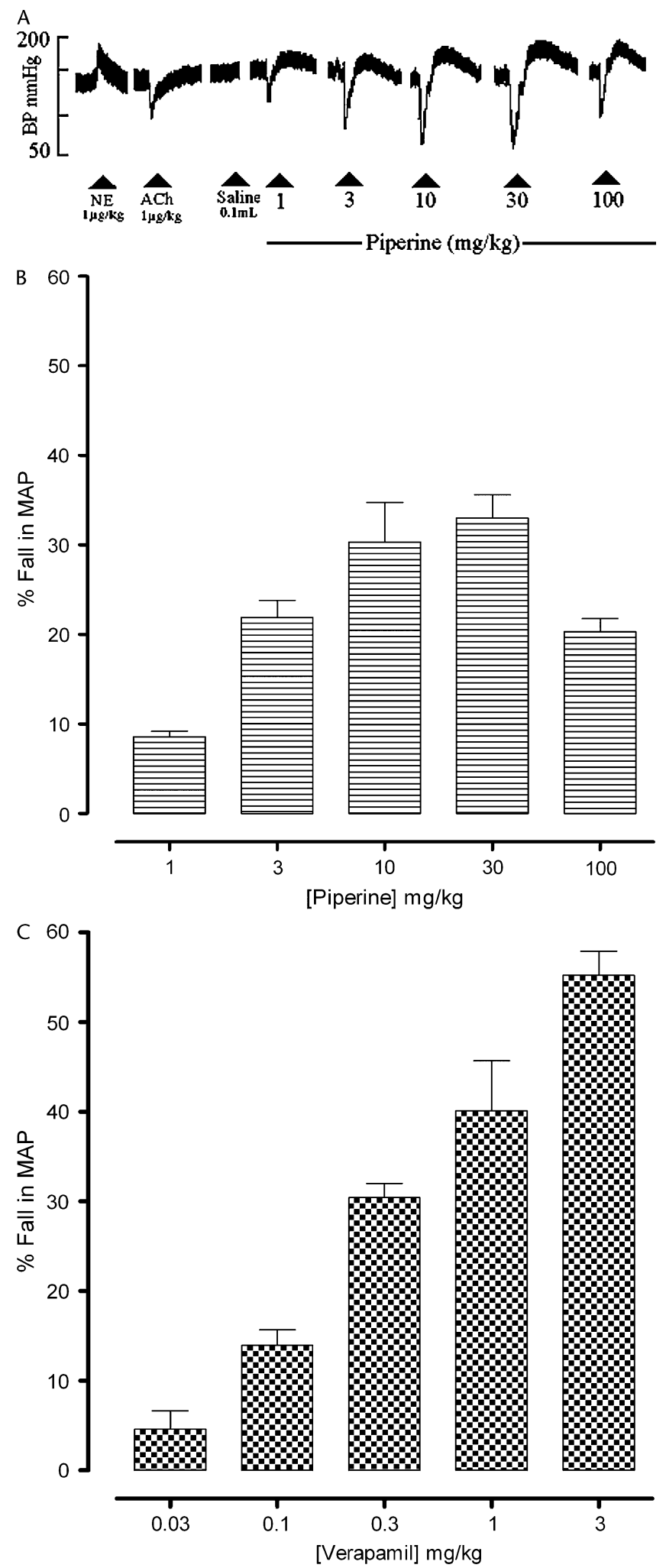

FIGURE 2. A representative tracing showing the effect of piperine (2A) on BP in normotensive anesthetized rats. Bar graph depicts the hypotensive effect of piperine (2B) and verapamil $(2 \mathrm{C})$ in normotensive anesthetized rats. Values shown are mean \pm SEM of 5 determinations. inhibited high $\mathrm{K}^{+}$-induced contractions, with $\mathrm{EC}_{50}$ value of $2.52 \mu \mathrm{M}(95 \% \mathrm{CI}, 1.78$ to 3.58$)$ (Figure $5 \mathrm{~A})$. When piperine was tested on baseline resting tension in normal Krebs solution, piperine was found to be without contractile effect, similar to verapamil.

\section{Effect on Bovine Coronary Artery}

In isolated bovine coronary arterial rings, cumulative addition of piperine and verapamil caused inhibition of contractions induced by high $\mathrm{K}^{+}$, with respective $\mathrm{EC}_{50}$ values of 7.5 (95\% CI, 5.70 to 9.84$)$ and $0.12 \mu \mathrm{M}$ (95\% CI, 0.08 to 0.16) (Figure 6). When piperine was tested on baseline resting tension in normal Krebs solution, piperine was found devoid of contractile effect.

\section{DISCUSSION}

In view of the potential calcium channel blocking effect of compounds containing piperidine, ${ }^{10-12}$ we assessed piperine for its possible antihypertensive effect and subsequently for vascular reactivity. When tested in anesthetized normotensive rats, intravenous administration of piperine caused a dosedependent ( 1 to $10 \mathrm{mg} / \mathrm{kg}$ ) fall in MAP. At the next higher dose $(30 \mathrm{mg} / \mathrm{kg})$, the effect was similar to the previous dose $(P>$ 0.05), whereas the BP-lowering effect declined with next higher dose. Moreover, at each dose of piperine, BP decrease was followed by a small increase in the response that returned to normal. These data suggest that piperine possesses a BPlowering effect along with some vasoconstricting mechanism(s) that dose-dependently restrict further decreases in BP, whereas verapamil caused consistent dose-dependent decrease in BP. BP is the product of cardiac output and vascular resistance, ${ }^{23}$ we studied the underlying mechanism(s) of piperine on $\mathrm{BP}$ in isolated cardiovascular preparations. In nonworking isolated rabbit heart, piperine attenuated $(70 \%)$ the force and rate of ventricular contractions and coronary flow at lower concentrations, whereas the next higher concentration was without further increase in response. Hence the results of in vivo and in vitro experiments are showing partial inhibitory effect of piperine.

The partial inhibitory effect of piperine suggests the involvement of some interfering mechanism that opposes the complete inhibition of all the observed variables, whereas verapamil caused complete inhibition of all the observed variables and finally blocked the working of the heart. Furthermore, the data of Langendorrf's heart indicate the direct effect of piperine on the myocardium because the autonomic reflexes are absent in the Langendorrf's preparations, which could confound in intact animal. ${ }^{24}$ Moreover, piperine is found to be different from verapamil, with CCB being partially effective on the force, rate, and coronary flow without causing cardiac arrest, whereas verapamil is clinically known to cause AV blockade and complete heart arrest. ${ }^{25}$ Calcium channel antagonists are known to cause AV block and cardiac slowing with negative inotropic effect, which results from the inhibition of the slow inward $\mathrm{Ca}^{2+}$ current during the action potential plateau. ${ }^{25}$ The negative inotropic and chronotropic effects of piperine may be the outcome of calcium channel blockade in the cardiac muscle, but its 
FIGURE 3. Effects of piperine (A) and verapamil $(B)$ on force and rate of ventricular contraction and coronary flow in nonworking isolated rabbit heart in Langendorrf's experiments. Values shown are mean \pm SEM of 5 determinations.

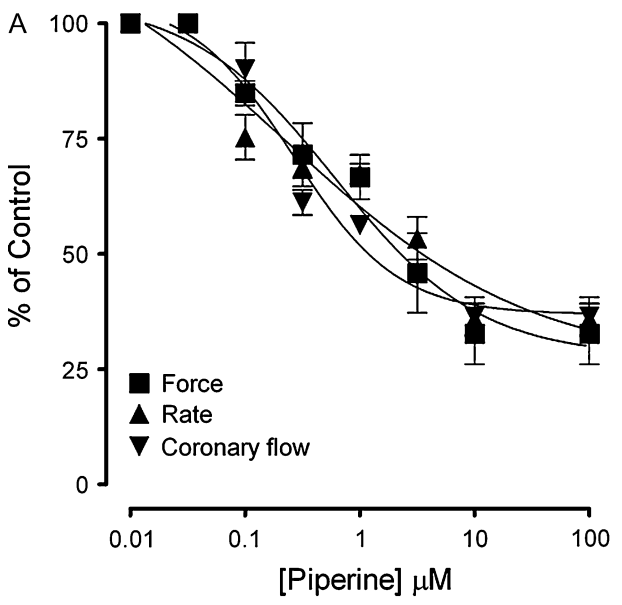

inability to cause cardiac arrest is indicating some additional mechanism, possibly interfering with inhibitory response beyond certain limit, and this property may offer some therapeutic merit, particularly when the cardiac suppression of calcium channel blockers such as verapamil is also considered as a side effect when used in a weak heart or when combined with other cardiosuppressants, such as beta adrenoceptor

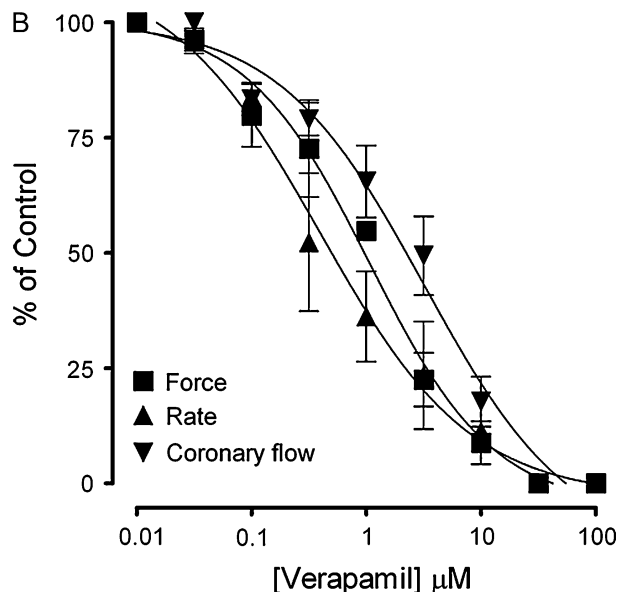

FIGURE 4. Upper panel shows the concentration-dependent inhibitory effect of piperine $(A)$ and verapamil (B) on contractions induced by phenylephrine (PE) and high $\mathrm{K}^{+}$ and on the baseline tension in $\mathrm{Ca}^{2+}$-free medium in rabbit aorta. Lower panel shows the effects of piperine (4C) and verapamil (4D) on the $\mathrm{Ca}^{2+}$ concentration-response curves constructed in $\mathrm{Ca}^{2+}$-free medium in isolated rabbit aorta preparations. Values shown are mean \pm SEM of 3 determinations.
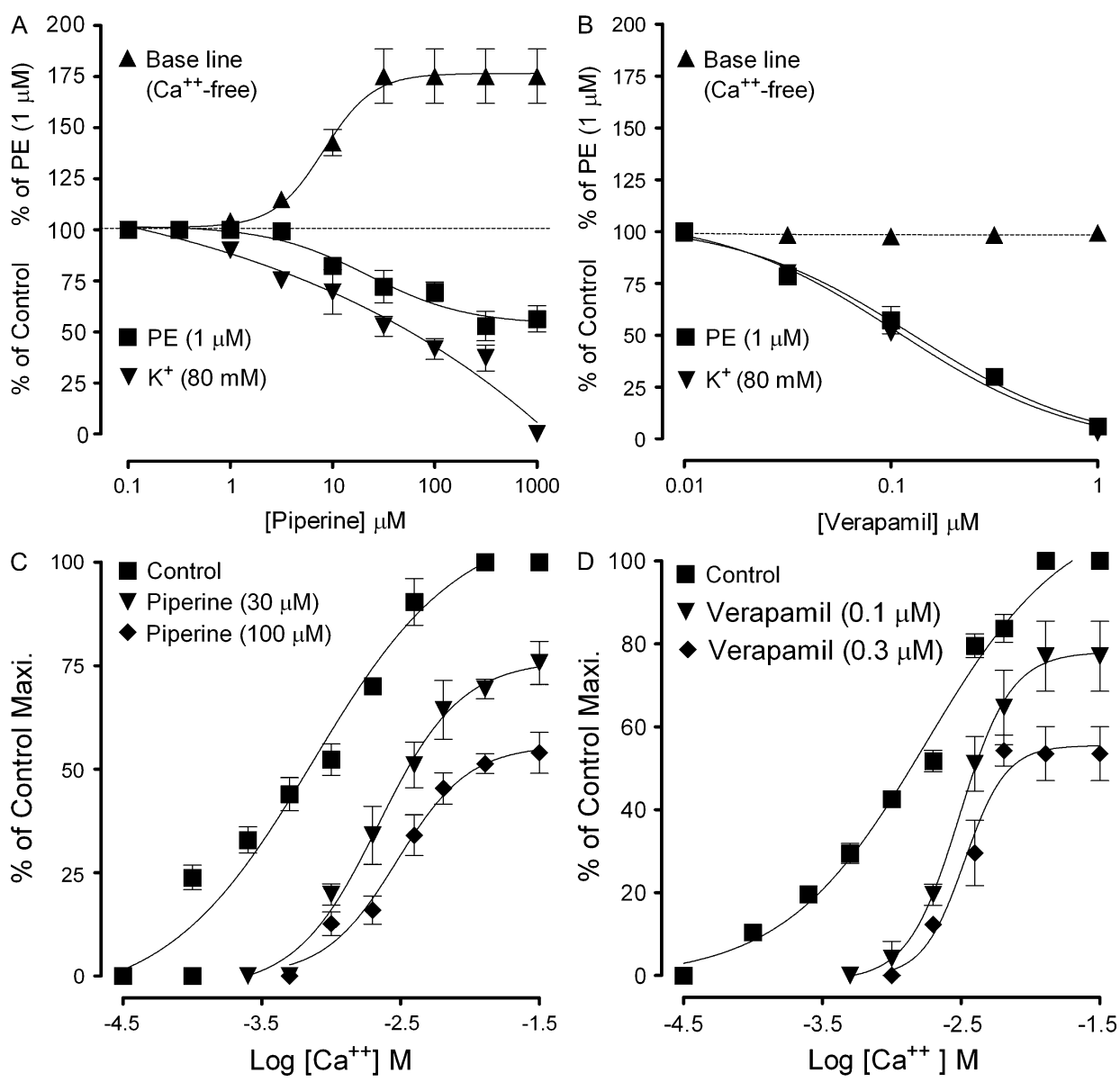
FIGURE 5. Endothelium-independent inhibitory effects of piperine $(A)$ and verapamil (B) in isolated rat aorta preparations. Values shown are mean \pm SEM of 3 determinations.

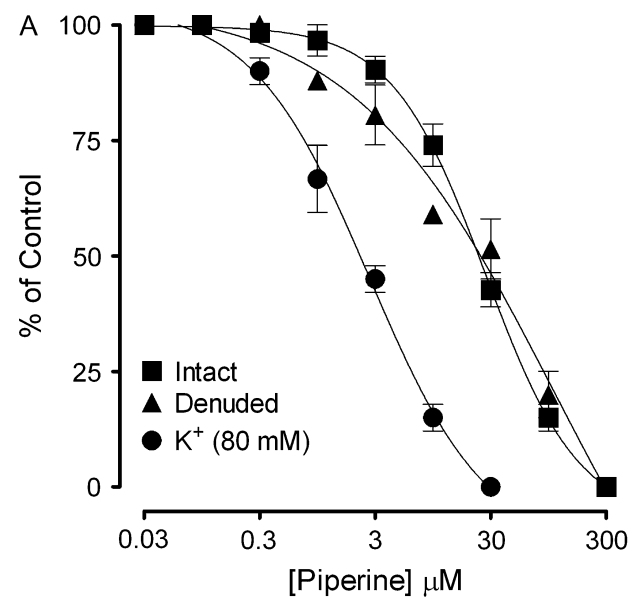

artery) to understand the underlying mechanism(s) of the BPlowering effect of piperine and possible species selectivity. Rabbit aorta was chosen to evaluate the effects of piperine on contractions induced by high $\mathrm{K}^{+}$and PE $(1 \mu \mathrm{M})$ and to distinguish between the effect on voltage-dependent calcium channels (VDCs) and receptor-operated calcium channels (ROCCs). ${ }^{26,27}$ When tested against the agonist-induced contractions, piperine caused complete inhibition of high $\mathrm{K}^{+}$-induced contractions, while it was found partially effective against the PE, suggestive of the selective effect on VDCs. Contraction of rabbit aortic preparations induced by high $\mathrm{K}^{+}$ depends on the influx of $\mathrm{Ca}^{2+}$ into the cells through VDCs, ${ }^{28}$ and a substance that can inhibit high $\mathrm{K}^{+}$-induced contractions is, therefore, considered to be a CCB. ${ }^{29}$ Thus the inhibitory effect of piperine against high $\mathrm{K}^{+}$precontractions suggests the presence of $\mathrm{CCB}$ effect. The $\mathrm{CCB}$ activity was further confirmed when pretreatment of the aortic rings with piperine shifted the $\mathrm{Ca}^{2+} \mathrm{CRCs}$ to the right, constructed in $\mathrm{Ca}^{2+}$-free medium similar to verapamil, a standard CCB. ${ }^{30}$

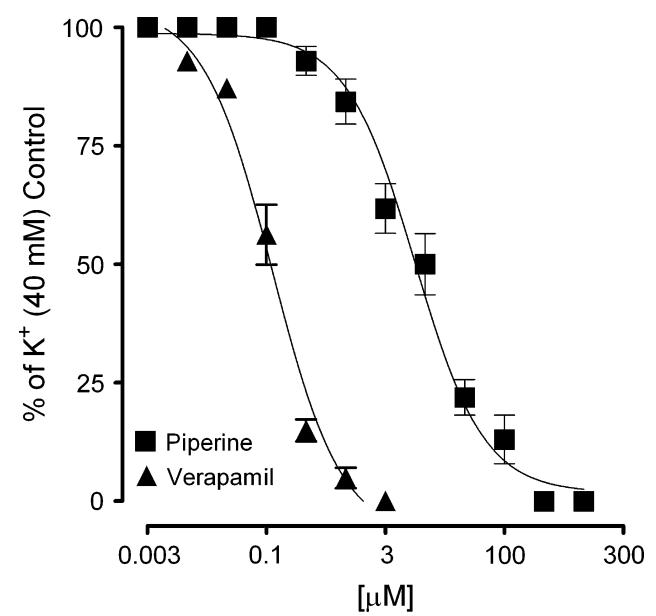

FIGURE 6. Shows the effects of piperine and verapamil against high $\mathrm{K}^{+}(40 \mathrm{mM})$ precontractions in bovine coronary arterial preparations. Values shown are mean \pm SEM of 3 determinations.

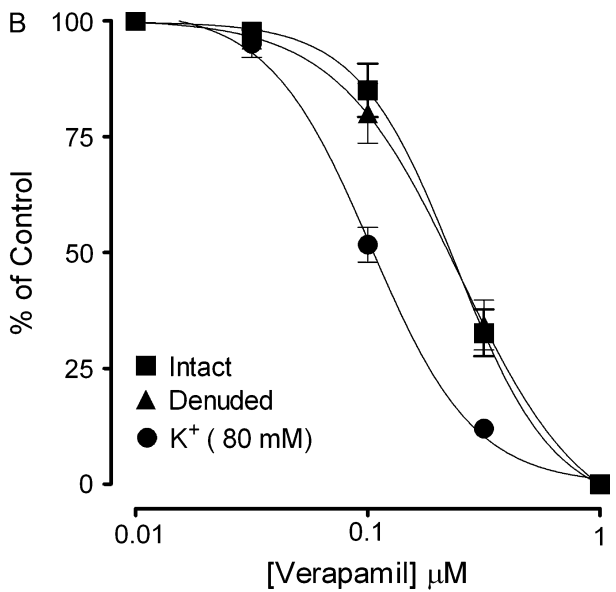

Phenylephrine is known to cause aortic contraction by increasing the intracellular $\mathrm{Ca}^{2+}$ concentration through the release of $\mathrm{Ca}^{2+}$ from sarcoplasmic reticulum (SR) and influx through ROCC. ${ }^{17}$ The partial inhibitory effect of piperine against the PE precontractions suggests its inhibitory effect, possibly mediated through inhibition of $\mathrm{Ca}^{2+}$ influx via ROCC, which is possibly counteracted by simultaneous release of $\mathrm{Ca}^{2+}$ from the $\mathrm{Ca}^{2+}$ store(s) under the influence of piperine. To test this hypothesis, piperine was tested on basal tension in $\mathrm{Ca}^{2+}$-free medium, where its cumulative addition caused a concentration-dependent contractile effect reaching approximately $75 \%$ of the PE $(1 \mu \mathrm{M})$ control. These data suggest that piperine causes the release of $\mathrm{Ca}^{2+}$ from the internal store; in normal Krebs solution, piperine was found without contractile effect, which may possibly explain the partial inhibitory effect against the PE precontactions and further suggests vascular modulator role of piperine mediated through $\mathrm{Ca}^{2+}$ movements. This finding also provides substantial evidence to the dosedependent BP-lowering effect of piperine at lower doses, which is probably due to the $\mathrm{CCB}$ effect. However, the decrease in BP-lowering response at higher doses and increase in BP after each dose is possibly due to the vasoconstrictive effect, mediated through $\mathrm{Ca}^{2+}$ release, which may partly explain the restricted decrease in BP and partial inhibitory effect on the force, rate, and coronary flow observed in the Langendorrf's heart preparations.

The vascular endothelium plays a pivotal role in modulating the vascular tone through the release of variety of substances. ${ }^{20}$ In isolated rat aorta preparations, piperine exhibited endothelium-independent inhibitory effect because the effect was not different $(P>0.05)$ from that observed in the denuded preparations and intact aortic rings incubated with L-NAME. When tested against high $\mathrm{K}^{+}$precontractions, piperine was found to be approximately 11 times more potent in rat than in rabbit aorta; similarly, piperine was without contractile effect on baseline tension in rat aorta preparations in $\mathrm{Ca}^{2+}$-free medium, indicating species selectivity.

The coronary artery of the heart is considered a major therapeutic target of calcium antagonists. ${ }^{31,32}$ Therefore, CCB activity of piperine was further tested against high $\mathrm{K}^{+}$ precontractions in isolated bovine coronary arterial 
preparations, wherein piperine produced relaxation of the precontactions in concentration-dependent manner. Depolarizing stimuli elicit contractions in coronary artery, promoting the entry of extracellular $\mathrm{Ca}^{2+}$ via membrane L-type $\mathrm{Ca}^{2+}$ channels. ${ }^{33}$ Therefore, relaxation induced by piperine against high $\mathrm{K}^{+}$precontracted bovine coronary arterial rings is likely due to the blockade of $\mathrm{Ca}^{2+}$ influx through membrane L-type $\mathrm{Ca}^{2+}$ channels similar to verapamil. Considering the pattern of relaxation of high $\mathrm{K}^{+}$precontracted vascular preparations, piperine was found to be more potent in rat than rabbit and bovine coronary arteries, indicating species selectivity. The difference in the inhibitory activity of piperine in these vascular preparations may also be due to the heterogeneous nature of $\mathrm{Ca}^{2+}$ channels. ${ }^{13}$

In summary, these data indicate that piperine possesses a CCB effect that is responsible for the cardiodepressant and vasodilator activities that provide the pharmacological basis for the BP-lowering effect, and the associated vasoconstrictor effects provide substantial evidence to the restricted decrease in BP and small increase in the BP followed by decline after each dose. Piperine is distinct from verapamil, owing to the presence of a vasoconstrictor effect possibly mediated through $\mathrm{Ca}^{2+}$ release, which may offer therapeutic merit by not allowing BP to decrease beyond a certain limit and which also supports the general belief that food remedies are mild to moderately effective with lesser side effects. Further electrophysiological studies would provide more insight into the molecular aspects of these mechanisms.

\section{REFERENCES}

1. Johri RK, Zutshi U. An Ayurvedic formulation 'Trikatu" and its constituents. J Ethnopharmacol. 1992;37:85-91.

2. de Mattos Duarte C, Verli H, de Araújo-Júnior JX, et al. New optimized piperineramide analogues with potent in vivo hypotensive properties. Eur J Pharm Sci. 2004;23:363-369.

3. Miyauchi T, Ishikawa T, Sugishita Y, et al. Involvement of calcitonin gene-related peptide in the positive chronotropic and inotropic effects of piperine and development of cross-tachyphylaxis between piperine and capsaicin in the isolated rat atria. J Pharmacol Exp Ther. 1989;248: 816-824.

4. Park BS, Son DJ, Park YH, et al. Antiplatelet effects of acidamides isolated from the fruits of Piper longum L. Phytomedicine. 2007;14: $853-855$

5. Ahmad M, Rahman MW, Rahman MT, et al. Analgesic principle from the bark of Careya arborea. Pharmazie. 2002;57:698-710.

6. Kumar S, Singhal V, Roshan R, et al. Piperine inhibits TNF-alpha induced adhesion of neutrophils to endothelial monolayer through suppression of NF-kappaB and IkappaB kinase activation. Eur J Pharmacol. 2007;575: $177-186$.

7. Li S, Wang C, Li W, et al. Antidepressant-like effects of piperine and its derivative, antiepilepsirine. J Asian Nat Prod Res. 2007;9:421-430.

8. Gevaert T, Vandepitte J, Hutchings G, et al. TRPV1 is involved in stretchevoked contractile changes in the rat autonomous bladder model: a study with piperine, a new TRPV1 agonist. Neurourol Urodyn. 2007;26: 440-450.

9. Srinivasan K. Black pepper and its pungent principle-piperine: a review of diverse physiological effects. Crit Rev Food Sci Nutr. 2007;47:735-748.
10. Taqvi SIH, Aftab MT, Ghayur MN, et al.(a) Synthesis and pharmacological screening of 1-(2́,s4-dimethoxyphrnacyl)-4-hdroxy-4-phenylpiperidinium bromide. Int $J$ Pharmacol. 2006;2:146-151.

11. Taqvi SIH, Nabeel MG, Gialni AH, et al. (b) Synthesis and smooth muscle selective relaxant activity of a piperidine analogue:1-(4'-fluorophenacy)4-Hydroxy-4-phenylpiperineeridinium chloride. Arch Pharmacal Res. 2006;29:34-39.

12. Taqvi SIH, Shah AJ, Gilani AH. Insight into the possible mechanism of antidiarrheal and antispasmodic activities of piperine. Pharm Biol. 2008, in press.

13. Koike K, Takayanagi I, Takiguchi S, et al. $\mathrm{Ca}^{2+}$ blocking action of stereoisomers of CI-951, (+)-CI-951, (NC)-1500 and (-)-CI-951 in the isolated muscle preparations. Gen Pharmacol. 1992;23:207-210.

14. National Research Council. Guide for the Care and Use of Laboratory Animals. Washington, DC: National Academy Press. 1996.

15. Gilani AH, Shah AJ, Janbaz KH, et al. Studies on antihypertensive and antispasmodic activities of Andropogaon muricatus Retz. Can J Physiol Pharmacol. 2007;85:911-917.

16. Langendorff O. Untersuchungen am Uberleberden Saugerleizen. Puflgers Arch Ges Physiol. 1895;61:291-332.

17. Karaki H, Ozaki H, Hori M, et al. Calcium movements, distribution, and functions in smooth muscle. Pharmacol Rev. 1997;49:157-230.

18. Guan YY, Kwan CY, Daniel EE. The effects of EGTA on vascular smooth muscle contractility in calcium free medium. Can J Physiol Pharmacol. 1988;66:1053-1056.

19. Furchgott RF, Zawadaski JV. The obligatory role of endothelial cells in the relaxation of arterial smooth muscle by acetylcholine. Nature. 1980;299: 373-376.

20. Jaffe EA. Physiological functions of normal endothelial cells. Ann NY Acad Sci. 1985;454:279-291.

21. Vanhoutte PM, Rubanyi GM, Miller VM. Modulation of vascular smooth muscle contraction by endothelium. Annu Rev Physiol. 1986;48:307-330.

22. Campbell WB, Gebremedhin D, Pratt PF, et al. Identification of epoxyeicosatrienoic acids as endothelium-derived hyperpolarizing factors. Circ Res. 1996;78:415-423.

23. Johansen PL. Hemodynamic effects of calcium antagonists in hypertension. In: Epstien, $\mathrm{M}$ ed. Calcium Antagonists in Clinical Medicine. Philadelphia: Hanley \& Belfus; 1992:69-88.

24. Balderston SM, Johnson KE, Reiter MJ. Electrophysiologic evaluation of cardiovascular agents in the isolated intact rabbit heart. $J$ Pharmacol Methods. 1991;25:205-213.

25. Rang HP, Dale MM, Ritter JM. Pharmacology. London: Churchill Livingstone; 1995.

26. Gilani AH, Shaheen F, Seed SA. Hypotensive action of coumarin glycosides from Daucus carota. Phytomdiecine. 2000;7:423-426.

27. Othman R, Ibrahim H, Mohd MA, et al. Vasorelaxant effects of ethylcinnamate isolated from Kaempleria galangal on smooth muscles of the rat aorta. Planta Med. 2002;68:652-655.

28. Bolton TB. Mechanism of action of transmitter and other substances on smooth muscles. Physiol Rev. 1979;59:606-718.

29. Godfraind I, Killer R, Wibo M. Calcium antagonism and calcium entry blockade. Pharmacol Rev. 1986;38:321-416

30. Hamilton TC, Weir SW, Weston AH. Comparison of the effect of BRL34915 and verapamil on electrical and mechanical activity on rat portal vien. Br J Pharmacol. 1986;88:103-111.

31. Willerson JT, Maseri A, Sleight P, et al. Calcium Antagonists. In: Willerson JET, Cohn JN, eds. Cardiovascular Medicine, Medical Treatment. New York: Churchill Livingstone; 1995:550-552.

32. Kalsner S. Coronary artery spasm: Multiple causes and multiple roles in heart disease. Biochem Pharmacol. 1995;49:859-871.

33. Kalsner S. Non-neurogenic contraction in isolated coronary arteries by brief electrical pulses. Cardiovasc Res. 1994;28:1835-1842. 